\title{
HISTIOCITOMA FIBROSO BENIGNO PROFUNDO: ACHADOS NA TOMOGRAFIA COMPUTADORIZADA E HISTOLOGIA*
}

\author{
Luciano Farage ${ }^{1}$, Mário Augusto Padula Castro ${ }^{1}$, Túlio Augusto Alves Macedo ${ }^{1}$, Eliana Chaves \\ Salomão², Tânia Alcântara Machado², Lincoln Pereira de Souza ${ }^{3}$, Luiz de Oliveira Freitas ${ }^{4}$
}

\begin{abstract}
Resumo Apresentamos imagens de tomografia computadorizada de um paciente de 83 anos de idade com histiocitoma fibroso benigno profundo, na face lateral da perna esquerda, com evolução de longa data. À tomografia computadorizada observamos massa bem delimitada, ovalada, e que apresentava intenso realce periférico com uso do meio de contraste iodado. Este é um tumor de partes moles pouco freqüente e com raros relatos dos seus aspectos de imagem.

Unitermos: Histiocitoma fibroso benigno profundo; Tomografia computadorizada; Tumores de partes moles.
\end{abstract}

Abstract Deep benign fibrous histiocytoma: computed tomography and histology findings.

We present the computed tomography images of an 83-year-old male patient with a deep benign fibrous histiocytoma at the lateral aspect of the left leg. Computed tomography images showed a well-defined mass with marked peripheral enhancement by iodinated contrast medium. Only few reports of this rare soft tissue tumor can be found in the literature.

Key words: Deep benign fibrous histiocytoma; Computed tomography; Soft tissue tumors.

\section{INTRODUÇÃO}

O histiocitoma fibroso benigno (HFB) é um tumor comum ${ }^{(\mathbf{1 , 2})}$ e com grande espectro de apresentação: cutâneo (forma mais comum), tecidos profundos (forma mais rara) e óssea ${ }^{(1-3)}$.

No osso faz parte do grupo dos defeitos metafisários fibrosos, que varia desde lesões derivadas de defeito de desenvolvimento até neoplasias verdadeiras, como $\mathrm{o} \mathrm{HFB}^{(4-7)}$. Os achados de imagem, já bem descritos, incluem lesões líticas da metáfise e sinal intermediário nas seqüências ponderadas em $\mathrm{T} 1$ à ressonância magnética. Ocorre, mais freqüentemente, no fêmur ou na tíbia e em crianças e adultos jovens $^{(4-7)}$. Na pele ocorre, com frequiência, como lesão pigmentada, cujo diagnóstico diferencial mais importante é o melano-

* Trabalho realizado no Setor de Radiologia do Hospital de Clínicas (HC) da Universidade Federal de Uberlândia (UFU), Uberlândia, MG.

1. Médicos Residentes de Radiologia do HC-UFU.

2. Professoras Adjuntas de Patologia, Departamento de Clínica Médica, da Faculdade de Medicina (Famed) da UFU.

3. Professor Assistente de Radiologia, Departamento de Clinica Médica, da Famed-UFU, Membro Titular do Colégio Brasileiro de Radiologia e Diagnóstico por Imagem (CBR).

4. Professor Adjunto de Radiologia, Departamento de Clínica Médica, da Famed-UFU, Chefe do Setor de Radiologia do HC UFU, Membro Titular do CBR.

Endereço para correspondência: Dr. Lincoln Pereira de Souza. Praça Coronel Carneiro, 105, ap. 1101, Fundinho. Uberlândia, MG, 38140-218. E-mail: pereiradesouza@uol.com.br

Recebido para publicação em 18/12/2003. Aceito, após revisão, em 13/2/2004. $\mathrm{ma}^{(\mathbf{1})}$. Como é excisado com menos de 3 $\mathrm{cm}$, não há relato dos aspectos de imagem deste tumor.

A forma profunda do HFB é bastante rara, contando com menos de $5 \%$ dos ca$\operatorname{sos}^{(3)}$. Ocorre em adultos e se apresenta como massa indolor, de crescimento lento. Os locais mais freqüentes são as extremidades inferiores, a cavidade abdominal e cabeça e pescoço. Nestes locais deriva do tecido subcutâneo ou muscular esqueléti$\operatorname{co}^{(\mathbf{2 , 3 , 8})}$. São escassos na literatura os relatos dos seus aspectos de imagem.

Apresentamos os achados tomográficos, histológicos e imuno-histoquímicos desta neoplasia.

\section{RELATO DO CASO}

Paciente de 83 anos de idade, sexo masculino, apresentava tumor pigmentado e ulcerado na porção lateral da perna esquerda, com evolução de cinco anos. O exame físico mostrou massa ovalada, de consistência elástica, pigmentada, medindo aproximadamente $8,0 \times 8,0 \mathrm{~cm}$, ulcerado na porção central.

A radiografia em perfil mostrava estrutura óssea íntegra e aumento das partes moles, na porção lateral da perna esquerda (Figura 1).

A tomografia computadorizada mostrava tumor pediculado, de $8,0 \times 8,0 \mathrm{~cm}$, na

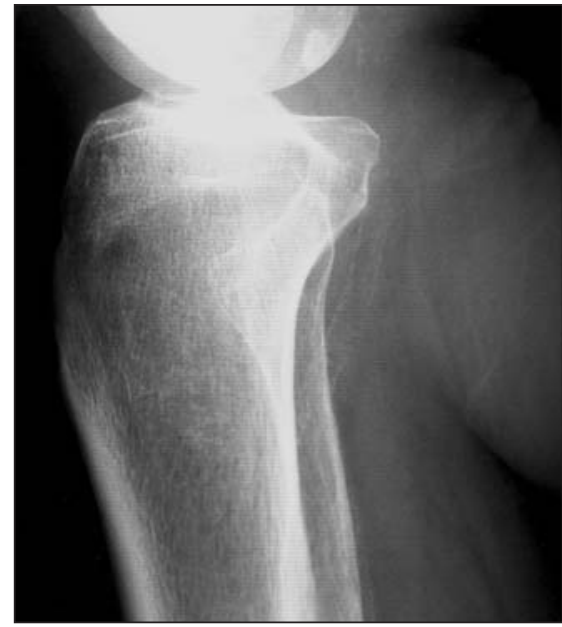

Figura 1. Radiografia em perfil da perna esquerda mostra estrutura óssea integra, com aumento das partes moles.

porção lateral da perna esquerda, na altura do platô tibial, sem comprometimento dos planos musculares ou alterações ósseas, e com área de aspecto cístico, mostrando conteúdo com densidade de partes moles (20 UH) (Figura 2A) e com intenso reforço pelo meio de contraste na periferia da lesão (Figura 2B).

A avaliação histológica revelou neoformação tecidual constituída por células fusiformes, às vezes de aspecto histiocístico, com poucas atipias e citoplasma mal definido, ora amplo e claro, ora espumoso. Entre elas pode-se observar algumas células 


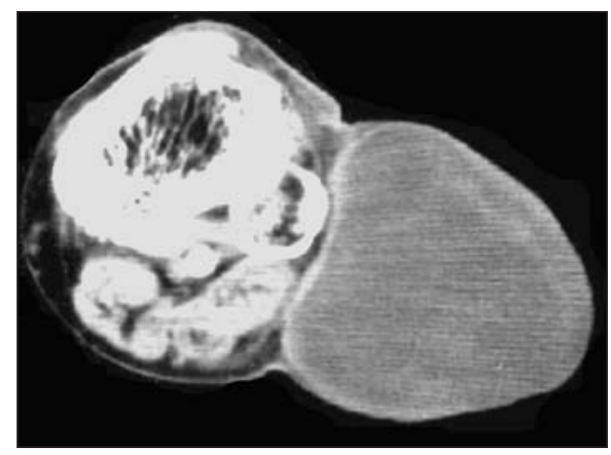

A

multinucleadas e poucos linfócitos. São vistas áreas de matriz eosinofílica, às vezes de aspecto condróide e com alguns depósitos de hemossiderina (Figura 3) e poucas figuras de mitoses (4/10 em campo de grande aumento).

O estudo imuno-histoquímico descartou neoplasias fusiformes de histiogênese muscular ou neural e confirmou o seu baixo índice de proliferação celular.

\section{DISCUSSÃO}

Os aspectos de imagem do HFB profundo, na extremidade, foram descritos pela primeira vez por Machiels et al. ${ }^{(3)}$, que, à tomografia computadorizada, identificaram lesão exofítica, com centro de baixa densidade e intenso realce periférico com uso do meio de contraste, e à ressonância magnética descreveram hipossinal central nas seqüências ponderadas em T1, hipersinal nas seqüências ponderadas em $\mathrm{T} 2$, e intenso realce marginal com o uso do meio de contraste.

Há outros dois relatos dos aspectos de imagem do HFB profundo, na cavidade abdominal, por Feix ${ }^{(9)}$, e na cavidade nasal, de recém-nascido, por Shrier et al. ${ }^{(\mathbf{8})}$, com aspectos de imagem semelhantes.

Os achados de imagem do HFB profundo, descritos na literatura ${ }^{(\mathbf{1 , 8}, \mathbf{9})}$, são semelhantes aos do nosso caso. Os exames de imagem são inespecíficos, sendo necessá-

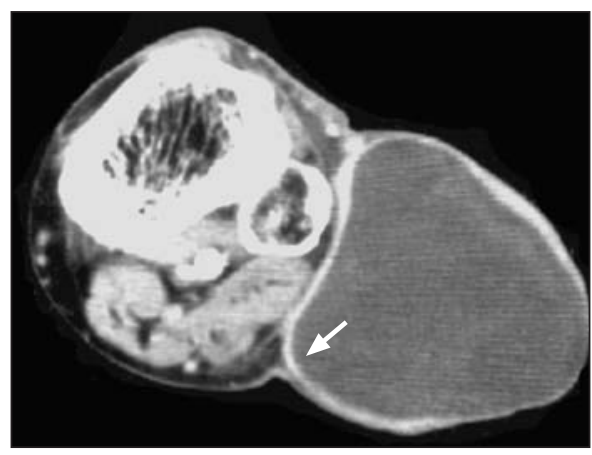

Figura 2. Tomografia computadorizada axial do joelho da perna esquerda mostra estrutura óssea íntegra e lesão exofítica com densidade de partes moles (20 UH). A: Imagem sem meio de contraste iodado. B: Imagem com meio de contraste, em que há intenso realce periférico (seta).

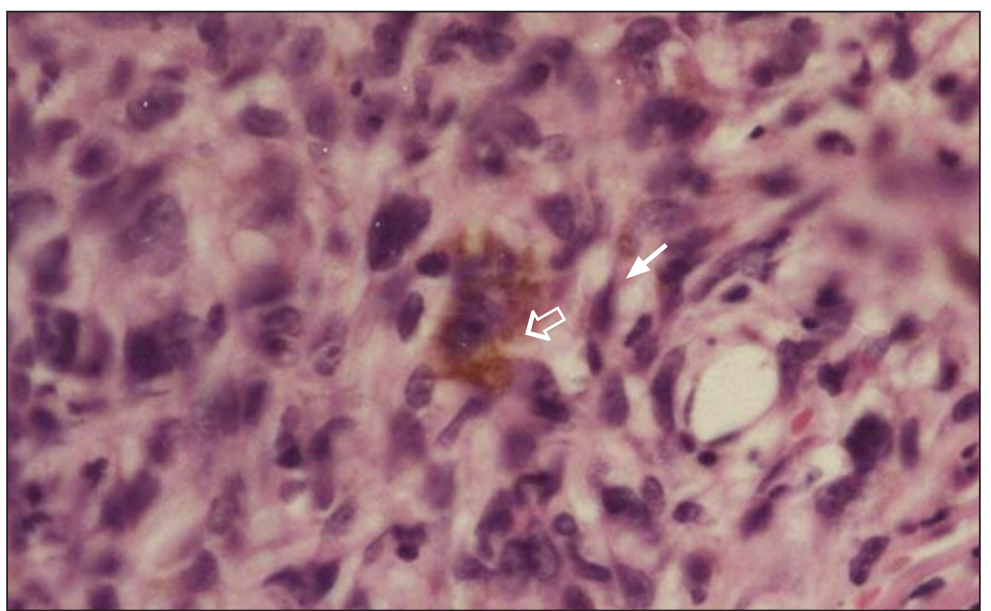

Figura 3. Aspecto histológico do tumor corado com hematoxilina-eosina em aumento de 400 vezes. Observar as células fusiformes (seta) e poucas atipias e depósitos de hemossiderina (contorno de seta).

rio o diagnóstico diferencial com histiocitoma fibroso maligno, metástase, tumor desmóide e schwannoma ${ }^{(\mathbf{1})}$. A imuno-histoquímica tem a função de afastar outras lesões ${ }^{(1,2,3,8)}$.

\section{REFERÊNCIAS}

1. Murphy GF, Mihn MC. Histiocytoma fibrous benign. In: Cotran RS, Kumar V, Robbins SL, eds. Pathologic basis of disease. 5th ed. Philadelphia, PA: WB Saunders, 1994:1188-9.

2. Weiss SW, Goldblum JR. Benign fibrous tissue tumors. In: Weiss SW, Goldblum JR, eds. Enzinger and Weiss' soft tissue tumors. 4th ed. St Louis, MO: Mosby, 2001:441-68.

3. Machiels F, De Maeseneer M, Chaskis C, Bourgain C, Osteaux M. Deep benign fibrous histiocytoma of the knee: CT and MR features with pathologic correlation. Eur Radiol 1998;8:989-91.
4. Destouet JM, Kyriakos M, Gilula LA. Fibrous his tiocytoma (fibroxanthoma) of a cervical vertebra. A report with a review of the literature. Skeletal Radiol 1980;5:241-6.

5. Clark TD, Stelling CB, Fechner RE. Benign fibrous histiocytoma of the left 8th rib. Case report 328 . Skeletal Radiol 1985;14:149-51.

6. Hamada T, Ito H, Araki Y, Fujii K, Inoue M, Ishida O. Benign fibrous histiocytoma of the femur: review of three cases. Skeletal Radiol 1996;25:25-

7. Smith SE, Kransdorf MJ. Primary musculoskeletal tumors of fibrous origin. Semin Musculoskelet Radiol 2000;4:73-88.

8. Shrier DA, Wang AR, Patel U, Monajati A, Chess P, Numaguchi Y. Benign fibrous histiocytoma of the nasal cavity in a newborn: MR and CT findings. AJNR 1998;19:1166-8.

9. Feix I. A benign histiocytoma of the retroperitoneum. Aktuelle Radiol 1993;3:182-3. 